This is a revised personal version of the text of the final journal article, which is made available for scholarly purposes only, in accordance with the journal's author permissions. The full citation is:

Zhang Y. and Banks C. J. (2013) Impact of different particle size distributions on anaerobic digestion of the organic fraction of municipal solid waste. Waste Management 33, 297-307. doi: 10.1016/j.wasman.2012.09.024

\title{
Impact of different particle size distributions on anaerobic digestion of the organic
}

\section{fraction of municipal solid waste}

\section{Author names and affiliations}

Y. Zhang ${ }^{1}$, C. J. Banks

Faculty of Engineering and the Environment, University of Southampton, Southampton SO17 1BJ, UK

\footnotetext{
Abstract Particle size may significantly affect the speed and stability of anaerobic digestion, and matching the choice of particle size reduction equipment to digester type can thus determine the success or failure of the process. In the current research the organic fraction of municipal solid waste was processed using a combination of a shear shredder, rotary cutter and wet macerator to produce streams with different particle size distributions. The pre-processed waste was used in trials in semi-continuous 'wet' and 'dry' digesters at organic loading rate (OLR) up to $6 \mathrm{~kg}$ volatile solids (VS) $\mathrm{m}^{-3} \mathrm{day}^{-1}$. The results indicated that while difference in the particle size distribution did not change the specific biogas yield, the digester performance was affected. In the 'dry' digesters the finer particle size led to acidification and ultimately to process failure at the highest

1 * Corresponding author: Tel.: +44 (0)2380 592188; fax: +44 (0)2380 677519; E-mail address: Y.Zhang@soton.ac.uk (Yue Zhang)
} 
OLR. In 'wet' digestion a fine particle size led to severe foaming and the process could not be operated above $5 \mathrm{~kg} \mathrm{VS} \mathrm{m}^{-3} \mathrm{day}^{-1}$. Although the trial was not designed as a direct comparison between 'wet' and 'dry' digestion, the specific biogas yield of the 'dry' digesters was $90 \%$ of that produced by 'wet' digesters fed on the same waste at the same OLR.

Keywords Anaerobic digestion; Municipal solid waste; Organic fraction; Particle size reduction; Dry shredding; Wet maceration

\section{Introduction}

It has often been argued that significant savings in both capital and operating costs of anaerobic digestion could be made by more rapid processing of input material. A number of researchers have suggested that this could be achieved by particle size reduction to allow more rapid reaction rates through increasing the surface area exposed to microbial attack (Chynoweth and Pullammanappallil, 1996; Hartmann and Ahring, 2006; Hills and Nakano, 1984; Kayhanian and Hardy, 1994; Sanders et al., 2000; Sharma et al., 1988; Yadvika et al., 2004). Other research has questioned the benefits of size reduction and drawn attention to other important factors. Chynoweth et al. (1993) and Gunaseelan (1997) both reported no significant digestion benefit from extensive reduction, and noted that comminution of materials may be uneconomic due to the energy input required. In unmixed 'dry' digestion systems that operate in batch or plug flow mode a small particle size may be disadvantageous as it can lead to 'slumping' of the waste within the reactor, making it more difficult to handle (Vandevivere et al., 2003). In batch systems that rely on percolation of liquid through the waste, a smaller 
particle size may also cause channelling and short-circuiting through the waste mass (Ten Brummeler, 1999).

As collected, the organic fraction of municipal solid waste (OFMSW) spans a wide range of particle sizes, and it is usually necessary to provide mechanical pretreatment before anaerobic digestion (Igoni et al., 2008). This gives a reduced size range compared to that in the original waste: but the mean particle size and the difference between the range of particles produced will depend on the degree and type of the treatment. Most particle size reduction studies have focussed on improving mechanical processes for the separation of waste fractions (Biala and Müller, 2001; Müller et al., 2001), while relatively few have considered the effect of size reduction method on the biological process. This is an important consideration, however, and it is likely that the preferred particle size distribution may be a compromise between promoting the maximum biological activity and maintaining physical and biochemical stability. It is also likely to depend on the type of digester used, and as 'wet' and 'dry' systems are now used in roughly equal numbers for the processing of OFMSW (De Baere and Mattheeuws, 2010) the effects should be determined in both. No comparative study on particle size effects in these two types of system has been reported to date, and direct comparison is complicated as there are many factors in addition to particle size that could influence the outcome. The current study was not designed as a direct comparison, but was intended to look at how a difference in particle size affects the performance of each process. The work used a single source stream of MSW, however, while most 'dry' digestion systems operate in the thermophilic range, some comparisons can thus be drawn between 'wet' and 'dry' systems under mesophilic conditions. 


\section{Materials and methods}

\subsection{Collection and sorting of waste}

MSW used in the study was obtained from Otterbourne waste transfer station (Hampshire, UK) operated by Veolia Hampshire Ltd. and serving residential kerbside collections in Southampton, Eastleigh and Winchester. To ensure consistency, where possible the waste was obtained in the same week of each month, on the same day of the week and from the same collection round. This round served the Winchester area, which has a separate source segregated kerbside collection of dry recyclable materials; the residual waste collected should therefore have a reduced content of plastic bottles, newspaper, metal cans and glass, as these materials were targeted for separate collection. The sampling involved taking a representative portion of approximately 400 $\mathrm{kg}$ of material discharged from the refuse collection vehicle (RCV). This was separated from the bulk of the waste using a mechanical shovel and placed in an open area, where a primary sort took place to remove obvious bulky non-biodegradable items such as electrical appliances and construction material residues. After this preliminary sort, which was typical of what might be achieved in preliminary conveyor belt separation at a materials recycling facility (MRF), a sub-sample of approximately $200 \mathrm{~kg}$ was further hand-sorted in the laboratory to remove non-biodegradable materials such as steel, glass, aluminium and plastics, leaving an enriched organic fraction for further processing. This remaining fraction was defined as OFMSW and included paper/cardboard/newsprint, kitchen waste, yard waste, and pet waste. In a full-scale process the above steps would be accomplished using automated magnetic/eddy current separators, trommel screens and densitometric methods in a series of mechanical preprocessing operations. 
2.2. Mechanical particle size reduction pre-treatment and particle size analysis

A schematic of the procedure for mechanical particle size reduction pretreatment is given in Fig. 1. The hand-sorted OFMSW was processed using a combination of methods. In the first instance all the waste was passed through a shear shredder (RS404S, Untha Ltd., Germany) with four counter-rotating shafts with a 20 $\mathrm{mm}$ jaw spacing and an $80 \mathrm{~mm}$ reject screen. After this treatment one portion of the waste was separated from the rest and used as feed in one pair of digesters in the dry digestion trial: this was the coarsest size fraction used. The remaining waste was passed through the shear shredder a second time to produce a smaller particle size range, and one third of this material was separated from the bulk and used in one pair of digesters in the wet digestion trial. A further one third of the material was then hand sorted using a sieve of mesh size $20 \mathrm{~mm}$ and any particles larger than $20 \mathrm{~mm}$ in the third dimension were extracted. This material was mainly newsprint and cardboard and was processed using a garden shredder with high-speed rotary blades (Alko-kober Ltd., Warwickshire, UK) to further reduce the size of this fraction. The processed material was then mixed back into the rest of the sample to produce a finer shredded-and-chopped fraction which was used in a second pair of dry digesters. The final third of the double-shredded material was then mixed with tap water to reduce the total solids concentration to $25 \%$, and passed through a macerating grinder (S52/010 Waste Disposer, IMC Ltd., UK) to produce a fine particle size material. This feed preparation technique was designed to simulate the action of hydro-pulping technology which has been adapted for this type of waste blending. The shredded and wet macerated material was used as feed to the second pair of wet digesters. 
When preparing the feed the weight of material required by each digester was taken into account so that an appropriate amount could be prepared, thus ensuring that all digesters were fed on the same batch of waste at a given time.

To determine the particle size distribution (PSD) of the different treatments using the shear shredder and the rotary blade cutter samples of $30 \mathrm{~kg}$ from each batch processed were analysed using a British Standard test sieve shaker (Endecotts Ltd., UK) for a 20 -min period, with mesh sizes of $37.5,20.0,13.2,6.7,5.0 \mathrm{~mm}$. The PSD was expressed as a percentage of the fresh weight present in each of a number of defined size classes. To determine the particle size of the wet macerated material it was diluted to give a slurry with a solids content of approximately $5 \%(\mathrm{w} / \mathrm{v})$, and then analysed using a wet sieving technique (Mahmoud et al., 2006). This was performed manually using a series of standard laboratory test sieves (Endecotts Ltd., UK) with mesh sizes of $4.75,3.18,2.00,1.00,0.60$, and $0.30 \mathrm{~mm}$. The screened undersize material $(<0.3 \mathrm{~mm})$ was collected in two 25-1 containers and centrifuged to concentrate the finest particles prior to weight determination. The waste retained on each of the larger mesh size sieves was rinsed off with tap water. The size-separated materials were then dried at $105^{\circ} \mathrm{C}$ to a constant weight, allowing the quantity of macerated OFMSW retained on each sieve to be expressed as a percentage of the total solids (TS) weight fraction.

To prepare material for the biochemical methane potential (BMP) test, $1 \mathrm{~kg}$ of waste that had been processed through the shear shredder was hand-cut to give a mean particle size of around $4 \mathrm{~mm}$. i.e. the resulting cut particles all passed through a 4.75 $\mathrm{mm}$ sieve but were retained on a sieve with $3.18 \mathrm{~mm}$ aperture. The material used in the test also contained the smaller fine particles naturally present in the waste. A sample that had been processed by the shear shredder and then wet macerated was also tested. 


\subsection{BMP assay}

The BMP test was carried out in five continuously-mixed digesters of 5-1 working capacity at $36 \pm 1{ }^{\circ} \mathrm{C}$. Two digesters were charged with the shear shredded waste that had been further reduced to a mean particle size of $4 \mathrm{~mm}$. Two digesters were charged with the shredded and macerated waste, and one digester was run as a control without substrate addition. The inoculum was obtained from a mesophilic digester at Millbrook Wastewater Treatment Works (WWTW) (Southampton, UK) and was sieved through a 1-mm mesh before 51 was added to each digesters. The test materials was added to give an initial concentration of $5 \mathrm{~g}$ volatile solids (VS) $\mathrm{l}^{-1}$, giving an inoculum:substrate ratio of $4.5: 1$ on a VS basis.

\subsection{Semi-continuous trial - wet digestion}

The experiments were carried out in four 44-1 CSTR digesters (working volume 35 1) over a 15-month period. Each digester was constructed from a high density polyethylene (HDPE) cylinder of internal diameter $0.32 \mathrm{~m}$ and height $0.55 \mathrm{~m}$ fitted with top and bottom flange plates. The digesters were heated to $36 \pm 1{ }^{\circ} \mathrm{C}$ by an internal heating coil and continuously mixed using a picket fence stirrer connected by a gas-seal draught tube to a geared motor at $35 \mathrm{rpm}$ (see Fig. S1 in Supplemental materials for photograph and schematic diagram of wet digesters). Fresh feed was added via a port in the top plate, and digestate removed from the bottom via a drain tube. Biogas production from each digester was measured continuously using a tipping-bucket gas flow meter as described in Walker et al. (2009). Digester temperature was continuously monitored by a sensor and logged via an interface to a computer. 
All four digesters were initially seeded with digestate from Millbrook WWTW and feeding commenced at an organic loading rate (OLR) of $2 \mathrm{~kg} \mathrm{VS} \mathrm{m}^{-3} \mathrm{day}^{-1}$. Two digesters were fed with the waste prepared by passing twice through the shear shredder and the other two with the shredded and wet macerated material as described above. The digesters were operated at a hydraulic retention time (HRT) of 30 days: 1.161 of digestate was removed from each digester every day, then the required amount of feed was added and the working volume was made up with tap water. The digesters were run for 60 days, then the OLR was increased to $3 \mathrm{~kg} \mathrm{VS} \mathrm{m}^{-3} \mathrm{day}^{-1}$ and conditions were allowed to stabilise. A similar procedure was followed for subsequent increases in OLR. The digesters were run for a total of 430 days which comprised periods of $60,30,142$, $60,64,42$, and 32 days at OLR of $2,3,4,4.5,5,5.5$, and $6 \mathrm{~kg} \mathrm{VS} \mathrm{m}^{-3}$ day $^{-1}$, respectively. Digestate $\mathrm{pH}$ was monitored daily; biogas composition and digestate solids, ammonia, alkalinity and volatile fatty acids (VFA) concentrations were analysed two to three times per week.

\subsection{Semi-continuous trial - dry digestion}

Digestion trials were carried out in four HDPE digesters each with a total volume of 301 . The digesters were maintained at around $36{ }^{\circ} \mathrm{C}$ by an external heating coil connected to a thermo-circulator (see Fig. S2 in Supplemental materials for the photo and schematic diagram of dry digesters). Biogas production from each digester was measured continuously using a tipping-bucket gas flow meter (Walker et al., 2009), and temperature was measured by sensors positioned in the bulk digestate material.

The digesters were inoculated with $60 \mathrm{~kg}$ of digestate from a previous highsolids digestion trial using a similar feedstock (Banks et al., 2008). The inoculum was 
homogenised and then evenly distributed between the digesters, which were then run at an OLR of $4 \mathrm{~kg} \mathrm{VS} \mathrm{m}^{-3}$ day $^{-1}$ for around 50 days without removing any digestate. In this way the digester contents were built up to a working volume of 251 at the start of the experiment. At this point the digestate had a $\mathrm{pH}$ of 8.6, total ammoniacal nitrogen (TAN) around $3700 \mathrm{mg} \mathrm{kg}^{-1}$ fresh matter, and VFA $<200 \mathrm{mg} \mathrm{kg}^{-1}$ fresh matter.

The dry digestion trial was started when the wet digestion trial had been running for 318 days, and ran for a total of 112 days. Two dry digesters were fed with the single-shredded material, and two with the shredded-and-chopped material. The digesters were fed once a week at an equivalent OLR of $6 \mathrm{~kg} \mathrm{VS} \mathrm{m}^{-3} \mathrm{day}^{-1}$. Between the weekly feeding there was no mixing of the digesters. The discharge and feeding procedure for each digester was as follows: (i) The amount of feedstock to be added was calculated based on the OLR and the feedstock VS content; (ii) All of the digestate in a digester was transferred into a separate container and mixed well; (iii) Fresh feedstock was placed into the empty digester, and the volume made up to 251 by returning some of the previously removed and mixed digestate; (iv) The digester contents were thoroughly mixed; (v) Any digestate not returned to the digester was used for analysis, and the excess was disposed of. The digesters were also weighed before and after each feeding and the weights recorded. In general, each digester received around $3 \mathrm{~kg}$ of fresh material every week and the total mass in each digester was $20.5-21.5 \mathrm{~kg}$ after feeding, subject to slight variations in the solids content of different batches of OFMSW during the trial period.

\subsection{Analytical methods}


TS and VS were measured according to Standard Method 2540 G (APHA, 2005). For dry digestion samples, pH, VFA, alkalinity and TAN concentrations were determined by mixing the sample with deionised water (1:5) for $15 \mathrm{~min}$ and then testing the supernatant, with the results expressed as mg per kg digestate. $\mathrm{pH}$ was measured using a Jenway $3010 \mathrm{pH}$ meter (Barloworld Scientific Ltd., UK) calibrated in buffers at pH 4.0, 7.0 and 9.2 (Fisher Scientific, UK). VFA were analysed using a Shimadzu GC2010 gas chromatograph (Shimadzu, Japan) with a flame ionisation detector. Alkalinity was measured by titration of the digestate supernatant with $0.25 \mathrm{~N} \mathrm{H}_{2} \mathrm{SO}_{4}$ to endpoints of pH 5.75 and 4.30, in order to allow calculation of total (TA), partial (PA) and intermediate alkalinity (IA) (Ripley et al., 1986). TAN in digestate supernatant, reacted with hypochlorite and salicylate ions in the presence of sodium nitroprusside to form a coloured compound, was measured using a Cecil 3000 series UV-Visible Scanning Spectrophotometer (Cecil Instruments Ltd., UK) at 655 nm (ISO7150-1, 1984).

Biogas composition was measured using a Varian CP 3800 GC with a gas sampling loop with argon as the carrier gas at a flow of $50 \mathrm{ml} \mathrm{min}^{-1}$. The $\mathrm{GC}$ was fitted with a Hayesep C column and a molecular sieve $13 \times\left(80-100\right.$ mesh) operated at $50^{\circ} \mathrm{C}$. Gas volumes were corrected to standard temperature and pressure (STP) of $101.325 \mathrm{kPa}$ and $0{ }^{\circ} \mathrm{C}$ as described in Walker et al. (2009).

\section{Results}

3.1. Feedstock characteristics and particle size distribution

Table 1 shows results of feedstock characterisation. $\mathrm{pH}$ fluctuated between 4.2 and 5.9, with TS in a range of 44-54\% of fresh matter. The VS values also varied from 
batch to batch. Other parameters, e.g. TAN and VFA, also presented great variations, due to the fact that some batches of waste contained more readily biodegradable material than others. These batches therefore had relatively low $\mathrm{pH}$ values with high ammoniacal nitrogen and VFA even before processing.

Typical particle size distributions (PSDs) resulting from the four different pretreatments are shown in Fig. 2. In the case of the shear shredder both single (Fig. 2a) and double pass material (Fig. 2b) showed a proportion of particles apparently larger than the jaw opening of the shredder. This was due to the material not being uniform in all dimensions: for example, some paper passed through the shredder as torn strands, which on sieve analysis lay flat against the sieve mesh. Although standard methods were used for the PSD, the application of these to OFMSW is unusual and for this reason there will always be limitations in this approach and the results are perhaps more comparable qualitatively than quantitatively (von Blottnitz et al., 2002). Most of the finer particles were naturally present in the waste rather than being physically changed as a result of the action of the cutting discs, but the fraction above $20 \mathrm{~mm}$ was significantly reduced compared to the raw material before feeding into the shredder. TS content was consistent for each size fraction, although it ranged from $44 \%$ to $54 \%$ for different batches of waste. Double processing (Fig. 2b) showed a reduction in particle sizes with most particles being in the 6.7-13.2 $\mathrm{mm}$ range compared to a high proportion in the 13.2-20 $\mathrm{mm}$ and $20-37.5 \mathrm{~mm}$ ranges when a single pass was used. Further reduction of the $>20 \mathrm{~mm}$ particles with the rotary cutter (Fig. 2c) increased the proportion in the $13.2-20 \mathrm{~mm}$ size range making this the biggest fraction after this treatment. 
The mean particle size of the wet macerated material (Fig. 2d) was around $2 \mathrm{~mm}$ with a substantial percentage $(33 \%)<0.3 \mathrm{~mm}$. The VS content of each fraction was measured and indicated that the smallest particle sizes had the lowest VS content (75\% of TS, compared with $90 \%$ for the fraction larger than $2 \mathrm{~mm}$ ). The fraction larger than 2 mm was mainly paper and cardboard fibres as these did not readily move around the sieve surface.

\subsection{BMP assay}

Fig. 3 shows the cumulative net specific methane yields in the BMP test. Methane production was calculated as an average value from the replicate results, and the error bars represent standard deviation. It can be seen that size reduction slightly increased the methane production rate in the first 15 days. Although the overall extent of digestion, as indicated by methane yield, appeared slightly greater in the digester with the $2 \mathrm{~mm}$ mean particle size $\left(0.35 \mathrm{~m}^{3} \mathrm{CH}_{4} \mathrm{~kg}^{-1} \mathrm{VS}\right.$ added $)$ than the $4 \mathrm{~mm}$ mean particle size $\left(0.34 \mathrm{~m}^{3} \mathrm{CH}_{4} \mathrm{~kg}^{-1} \mathrm{VS}\right.$ added $)$ the variation between the pairs of digesters was not significant, as can be seen from the overlapping error bars. The results thus indicated that reducing the particle size from $4 \mathrm{~mm}$ to an average of $2 \mathrm{~mm}$ did not notably increase the extent of degradation. The kinetic difference at the beginning of the test may also be unimportant if the retention time in continuous digestion is longer than 15 days.

\subsection{Semi-continuous CSTR 'wet' digestion trial}

Table 2 summarises the process performance and digestion parameters at different OLR. Performance of duplicate digesters showed good agreement, and the 
results presented are the average value and standard deviation of the data from the last 10 days of operation for each of the OLR.

At an OLR of 2, 3, and $4 \mathrm{~kg} \mathrm{VS} \mathrm{m}^{-3}$ day $^{-1}$, all four digesters fed with the dry double-shredded and the wet macerated waste showed more or less identical performance. The average VS removal at steady state was between 60 and $70 \%$ and specific biogas yield was in the range $0.54-0.56 \mathrm{~m}^{3} \mathrm{~kg}^{-1} \mathrm{VS}$ added. The exception to this was with the first batch of OFMSW which gave a yield of $0.43-0.46 \mathrm{~m}^{3} \mathrm{~kg}^{-1} \mathrm{VS}$ at OLR of $2 \mathrm{~kg} \mathrm{VS} \mathrm{m}^{-3}$ day $^{-1}$. This batch was known to have a high percentage of garden waste, as well as paper, cardboard, and pet bedding material, and therefore probably showed lower biogas production because of its high ligno-cellulose content. Although there was some variability between later batches they all contained a higher proportion of food waste and appeared typical of waste from this type of collection system.

On increasing the OLR to $4.5,5.0$ and $5.5 \mathrm{~kg} \mathrm{VS} \mathrm{m}^{-3}$ day $^{-1}$ there was no observable loading shock and no difference in process efficiency between the pairs of digesters fed with different-sized waste. As expected the volumetric biogas production (VBP) increased with increasing OLR and was over $2.5 \mathrm{~m}^{3} \mathrm{~m}^{-3}$ day $^{-1}$ at loading rates above $4.5 \mathrm{~kg} \mathrm{VS} \mathrm{m}^{-3} \mathrm{day}^{-1}$. The biogas methane content remained between 56 and $59 \%$ over batches. For the digesters fed with wet macerated waste, however, when an OLR of $5.5 \mathrm{~kg} \mathrm{VS} \mathrm{m}^{-3}$ day $^{-1}$ was maintained severe foaming began to occur as a result of gas entrainment within the digestate, causing it to expand and fill the digesters past their usual working volume. This led to blocking of the biogas venting lines and pressure build-up in the digesters which caused the feed port stopper to blow out giving an uncontrolled release of digestate. This inevitably resulted in some loss of digestate and it was finally concluded it was not possible to increase the loading rate past this point 
under the designated operational strategy. No serious foaming occurred in the digesters fed on the coarser double-shredded waste and it was possible to raise the OLR to $6 \mathrm{~kg}$ $\mathrm{VS} \mathrm{m}^{-3}$ day $^{-1}$. Even at this high loading the digesters maintained a $\mathrm{pH}$ of 7.3, a VFA concentration $<100 \mathrm{mg} \mathrm{l}^{-1}$, a moderate TAN concentration $\left(\sim 1000 \mathrm{mg} \mathrm{N}^{-1}\right)$, and an IA/PA ratio less than 0.3 indicating successful stable digestion.

The results indicate reasonably uniform process efficiency and operating parameters at comparable loadings for the two different waste treatments (Table 2). The reasons for this consistency were mainly because a large portion of the OFMSW was paper/cardboard/newsprint, which is a two-dimensional material and could be torn apart during retention in a continuously-stirred liquid environment. This provided sufficient specific surface for micro-organism attack regardless of the original particle size; the behaviour of porous material such as bread was similar. In addition, after dry shear shredding, the majority of the food waste had been crushed and its structure broken up. There was no significant difference in the biogas yield from the material that had been shear shredded to that which had been macerated when operating at the same OLR. The difference in VS removal between the two pairs of digesters at OLR $2 \mathrm{~kg} \mathrm{VS} \mathrm{m}^{-3}$ day $^{-1}$ was due to a digester design fault which was subsequently rectified, and disappeared when the OLR was increased to $3 \mathrm{~kg} \mathrm{VS} \mathrm{m}^{-3}$ day $^{-1}$.

Biogas production curves for the 24-h period between feeds were also analysed, and examples are presented in Fig. 4. At an OLR of $3 \mathrm{~kg} \mathrm{VS} \mathrm{m}^{-3}$ day $^{-1}$ biogas was produced at an almost equal rate from both double-shredded and wet macerated OFMSW, with a more rapid rate of production in the early stages of the cycle (Fig. 4a); as expected this is symptomatic of a digester where the available substrate starts to become limited after 10-12 hours. At an OLR of $4 \mathrm{~kg} \mathrm{VS} \mathrm{m}^{-3}$ day $^{-1}$ a change in the 
shape of the daily biogas production curve can be seen (Fig. 4b). The digesters fed with wet macerated material had a faster initial rate of production, although the digesters fed with double-shredded material caught up afterwards, resulting in a similar total biogas production for the full 24-hour period.

Fig. 4c-f shows cumulative biogas production at OLR of 4.5, 5.0, 5.5 and $6.0 \mathrm{~kg}$ VS m${ }^{-3}$ day $^{-1}$. It can be seen that, as OLR $4.5 \mathrm{~kg} \mathrm{VS} \mathrm{m}^{-3} \mathrm{day}^{-1}$, the digesters fed with the wet macerated waste had a faster initial rate of production which began to slow down towards the end of the feeding cycle. In the digesters fed with the double-shredded waste the initial rate of reaction was slightly lower, but decreased more slowly than for the wet macerated feed. Therefore the total biogas production was still more or less the same as for the wet macerated feed, indicating a similar degree of stabilisation. Kinetic comparison between the pairs of digesters was not possible at OLR $6 \mathrm{~kg} \mathrm{VS} \mathrm{m}^{-3}$ day $^{-1}$, but the trend of biogas production rate with the shear-shredded feedstock was similar to that at $5.5 \mathrm{~kg} \mathrm{VS} \mathrm{m}^{-3}$ day $^{-1}$.

\subsection{Dry digestion trial}

The dry digestion trial ran for 112 days after the initial acclimatisation period. Results shown in Figs. 5-7 are average values taken from duplicate digesters and error bars represent standard deviation. Vertical dashed lines in Fig. 5 indicate when a change in input material took place as a result of a fresh batch of feedstock: this information is not shown on every figure. A rapid temperature drop to below $25{ }^{\circ} \mathrm{C}$ occurred soon after the start of the sixth feed cycle (day 36), when the thermostat failed. The system was fixed within $48 \mathrm{~h}$ and the temperature returned to $36{ }^{\circ} \mathrm{C}$ in $\sim 3$ days. This interruption affected digester performance during that week, as can be seen from the biogas 
production which fell from 0.4 to around $0.3 \mathrm{~m}^{3} \mathrm{~kg}^{-1} \mathrm{VS}$ added. It was thought that the digesters might still contain a large portion of the previously-loaded waste that had not been biodegraded, and it was therefore decided to suspend feeding in the following week to allow this to be consumed. In week 8 the normal weekly feed cycle was resumed.

For the first five cycles there was no clear difference between the different feedstocks in terms of biogas production (Fig. 5) and VS destruction (Fig. 6). Specific biogas production stabilised at $\sim 0.42 \mathrm{~m}^{3} \mathrm{~kg}^{-1} \mathrm{VS}$ added with a more or less constant $\mathrm{pH}$ of around 8.5, and VFA concentrations of 3000-4000 $\mathrm{mg} \mathrm{kg}^{-1}$ digestate with the majority as acetic acid. TAN concentrations were around $3500 \mathrm{mg} \mathrm{kg}^{-1}$ digestate, and the IA/PA ratio was below 0.45 (Fig. 6).

Biogas production for the first two feeding cycles is plotted in Fig. 7 and shows that the rate of production was almost equal for both pairs of digesters, being slightly more rapid in the early stages of the cycle. Biogas composition also changed from the 50:50\% $\mathrm{CH}_{4}$ and $\mathrm{CO}_{2}$ seen during the first two days after feeding to a methane concentration above $60 \%$ by day 3 ; this proportional split was then maintained until the next feeding. The change in gas composition indicated that hydrolysis, acidogenesis and acetogenesis were dominant immediately after fresh feedstock was added but were balanced by increased methanogenic activity in the latter part of the cycle.

Differences in the performance of the two pairs of digesters were observed after week 5. The biogas production for the digesters fed with single-shredded waste was stable at $\sim 0.48 \mathrm{~m}^{3} \mathrm{~kg}^{-1} \mathrm{VS}$ added, with a VS destruction of $57 \%$. Biogas yields from the digesters fed with waste processed using a shredder and rotary cutter showed a gradual fall in volume and a reduced methane content. $\mathrm{pH}$ also dropped below 8 at around 100 
days due to the accumulation of VFA to $20,000 \mathrm{mg} \mathrm{kg}^{-1}$ digestate, consisting of $18 \%$ acetic, $35 \%$ propionic and $26 \%$ butyric acid. The reduction in $\mathrm{pH}$ shifted the balance between free ammonia and ammonium ions and prevented free ammonia release into biogas, resulting the total ammoniacal nitrogen reached $>8000 \mathrm{mg} \mathrm{NH} \mathrm{N}_{3} \mathrm{Ng}^{-1}$ digestate towards the end of the trial. The IA/PA ratio in the digesters treating this material rose to 1.7 compared with 0.4 for the digester treating the coarser-size single-shredded waste. At this point the pair of digesters fed with the waste processed using a shredder and rotary cutter were considered to have failed.

As this failure was observed in both digesters at almost same time it can be regarded as reproducible, and consequently it is likely that the difference in feedstock PSD was responsible, as this was the only difference between the two pairs of digesters. Nothing in the experimental results provides a definitive reason why this should have occurred. The major difference between the waste streams appeared on visual examination to be the fluffy and fibrous nature of the paper and card component after processing with the rotary cutter. This gave the waste a high specific surface area which could effectively absorb the digestate moisture. The contents of the digesters fed on this material appeared drier than those of the digesters fed on the coarser single-shredded material, where the moisture appeared to be mainly on the surface of relatively bulky pieces. The mode of weekly batch feeding and the temperature drop in week 6 may also have contributed to the acidification of digestion of the finer feedstock, whereas digestion of the coarser feedstock may have been able to withstand these shocks due to the relatively longer hydrolysis and acidogenesis processes. Further investigation is needed, however, into how this may have affected the rate or nature of the microbial reactions. 


\subsection{Comparison of wet and dry digestion}

The performance and stability of dry and wet digesters fed respectively on waste pre-treated using different methods to produce different particle size distributions are given in Table 3. The slightly lower specific biogas production and VS destruction in the 'dry' digesters compared to that in the 'wet' digesters may simply be attributable to the fundamentally different modes of operation. The 'wet' digesters were completely mixed, well agitated and fed daily whereas the 'dry' digesters had no continuous mixing, and simulated a plug flow regime by the weekly batch feeding. This involved manually mixing the two components in a separate container outside the digesters and resulted in a lowering of the temperature and introduction of oxygen. Together these may have resulted in some inhibition to the process or in oxidation of some substrate via aerobic respiration rather than reduction to methane through methanogenesis. It is interesting to note that under mesophilic conditions in the current operating regime there appeared to be no advantage in high solids operation.

\section{Discussion}

\subsection{Batch BMP trials}

The batch tests carried out showed that particle size had little effect on either the kinetics of the digestion or the final BMP value. This is in agreement with the results of Chynoweth et al. (1993) who tested a variety of substrates and reported similar behaviour for particles in the millimetre-to-centimetre range. They considered, however, that particle size reduction to less than $1 \mathrm{~mm}$ affected the digestion kinetics in an unpredictable manner. Clarkson and Xiao (2000) also found no significant effect on the 
bioconversion rate of newsprint and office paper when prepared at different particle sizes ranging from ground material to whole sheets. Sharma et al. (1988) who carried out tests on several agricultural and forest residues did, however, show some differences when using particle of $0.40,1.0$ and 6.0 with a fall of between 7 and $10 \%$ in methane production between the largest and smallest particle sizes tested. Kivaisi and Eliapenda (1994) looked at particle sizes in the range $5 \mathrm{~mm}$ to $<0.85 \mathrm{~mm}$ for bagasse and coconut fibres, and showed degradation increased by over $40 \%$ and methane yields by an average of 30\%. Moorhead and Nordstedt (1993) using water hyacinth showed the highest cumulative 15-day biogas production at a particle size of $6.4 \mathrm{~mm}$, although total biogas and methane yields at 60 days were similar regardless of particle size. Mshandete et al. (2006) showed enhanced methane yield with sisal fibre when the particle size was reduced to around $2 \mathrm{~mm}$. Perez Lopez et al. (2005) tested the effect of particle size reduction on corn grains and whole crop maize silage which improved the methane production of both substrates, although the increase was less than $10 \%$ in both cases. Nopharatana et al. (2007) showed that the rate of digestion and the methane yield was not affected by two different size reduction methods when using MSW as substrate.

It thus seems that in some cases particle size reduction can have a positive effect, but this appears to be substrate specific and the results for the current study are in line with others for paper and readily degradable substrates, both of which appear to be more or less unaffected in their biogas potential by particle size reduction. This finding is further substantiated by the extensive work of Palmowski and Müller (2003), who looked specifically at degradation kinetics based on chemical composition as well as material form and structure. 


\subsection{Semi-continuous digestion}

Although there are fewer studies on the effect of particle size on biogas production in continuous or semi-continuous digestion compared to in batch trials, the findings follow the same trend as for the batch tests. For substrates with a high fibre content Hills and Nakano (1984) found mechanical pre-treatment for particle size reduction could enhance biogas production. Ghosh et al. (2000) found using refusederived fuel that a primary treatment with a flail mill, secondary treatment by shredding (average particle size $2.2 \mathrm{~mm}, 90 \%<25 \mathrm{~mm}$ ) and tertiary treatment using a hammer mill (average $1.1 \mathrm{~mm}, 90 \%<6 \mathrm{~mm}$ ) indicated that tertiary fiberisation was not necessary because the methane yield from secondary-shredded refuse was 9-14\% higher than from tertiary shredded material when both tested under both mesophilic and thermophilic conditions. In the current study it was also noted that the rotary cutter, which tended to break the fibre, could potentially give higher biogas yields but in practice this was probably offset by the tendency towards rapid acidification and inhibition in the dry digesters. In the 'wet' digesters the smaller particle size of the macerated material gave a faster biogas production kinetic but the overall biogas yield was the same. The faster kinetic could however have potentially allowed an increase in feed rate with an apparent increase in biogas productivity.

\section{Conclusions}

Careful consideration must be given to the method and extent of particle size reduction adopted depending on the digester types used, and the common assumption that a smaller mean particle size will automatically lead to improved performance is not necessarily correct. In the current work there was no increase in specific methane 
production as a result of particle size reduction in the 'wet' digestion system, although the gas production kinetic in the semi-continuous trials indicated that particle size reduction could increase the rate of reaction. At a high organic loading, use of wet macerated material led to operational difficulties because of gas entrainment within the digestate. In 'dry' digesters coarser single-shredded material was successfully treated at an OLR of $6 \mathrm{~kg} \mathrm{VS} \mathrm{m}^{-3} \mathrm{~d}^{-1}$, whereas the finer shredded and rotary cut material acidified leading to process failure. The specific methane production in the 'dry' digesters was slightly lower than in 'wet' digesters processing the same material. A number of operational factors could have influenced this, and further investigation is needed.

\section{Acknowledgements}

This research was funded by the Department for Environment, Food and Rural Affairs, UK under the Technologies Research Innovation Fund (TRIF) Programme. Views expressed herein are the authors' and not necessarily those of Defra.

\section{Appendix A. Supplementary material}

Supplementary data associated with this article can be found, in the online version, at http://dx.doi.org/10.1016/j.wasman.2012.09.024.

\section{References}

APHA, 2005. Standard Methods for the Examination of Water and Wastewater, twentyfirst ed. American Public Health Association, American Water Works Association, Water Environment Federation, Washington, USA. 
Banks, C.J., Zhang, N., Zhang, Y., 2008. High solids anaerobic digestion of biodegradable municipal waste: effect of organic loading rate on digester performance. Proceedings of 5th IWA International Symposium on Anaerobic Digestion of Solid Wastes and Energy Crops, Hammamet, Tunisia, 25-28 May 2008.

Biala, J., Müller, W., 2001. Bio-mechanical waste treatment as Part of an integrated waste management stategy and a means of meeting UK and EU Waste reduction targets. Proceedings of 8th International Waste Management and Landfill Symposium, Cagliari, Italy, 1-5 October 2001. Vol 1, pp. 399-408.

Chynoweth, D.P., Pullammanappalli, P., 1996. Anaerobic digestion of municipal solid wastes, in: Palmisano, A.C., Barlaz, M.A. (Eds.), Microbiology of solid waste. CRC Press, Boca Raton, pp. 71-113.

Chynoweth, D.P., Turick, C.E., Owens, J.M., Jerge, D.E., Peck, M.W., 1993. Biochemical methane potential of biomass and waste feedstocks. Biomass Bioenerg. 5, 95-111.

Clarkson, W.W., Xiao, W., 2000. Bench-scale anaerobic bioconversion of newsprint and office paper. Water Sci. Technol. 41, 93-100.

De Baere, L., Mattheeuws, B., 2010. Anaerobic digestion of MSW in Europe. Biocycle $51,24-26$.

Ghosh, S., Henry, M.P., Sajjad, A., Mensinger, M.C., Arora, J.L., 2000. Pilot-scale gasification of municipal solid wastes by high-rate and two-phase anaerobic digestion (TPAD). Water Sci. Technol. 41, 101-110.

Gunaseelan, V.N., 1997. Anaerobic digestion of biomass for methane production: A review. Biomass Bioenerg. 13, 83-114. 
Hartmann, H., Ahring, B.K., 2006. Strategies for the anaerobic digestion of the organic fraction of municipal solid waste: an overview. Water Sci. Technol. 53, 7-22.

Hills, D.J., Nakano, K., 1984. Effects of particle size on anaerobic digestion of tomato solid wastes. Agric. Wastes 10, 285-295.

Igoni, A.H., Ayotamuno, M.J., Eze, C.L., Ogaji, S.O.T., Probert, S.D., 2008. Designs of anaerobic digesters for producing biogas from municipal solid-waste. Appl. Energy $85,430-438$

ISO7150-1, 1984. Water quality - Determination of ammonium - Manual spectrometric method.

Kayhanian, M., Hardy, S., 1994. The impact of 4 design parameters on the performance of a high-solids anaerobic digestion of municipal solid waste for fuel gas production. Environ. Technol. 15, 557-567.

Kivaisi, A.K., Eliapenda, S., 1994. Pre-treatment of Bagasse and Coconut Fibers for Enhanced Anaerobic Degradation by Rumen Microorganisms. Proceedings of World Renewable Energy Congress III - Climate Change, Energy and the Environment, Reading, England, 11-16 September 1994. Pergamon-Elsevier Science Ltd, pp. 791-795.

Mahmoud, N., Zeeman, G., Gijzen, H., Lettinga, G., 2006. Interaction between digestion conditions and sludge physical characteristics and behaviour for anaerobically digested primary sludge. Biochem. Eng. J. 28, 196-200.

Mshandete, A., Bjornsson, L., Kivaisi, A.K., Rubindamayugi, M.S.T., Mattiasson, B., 2006. Effect of particle size on biogas yield from sisal fibre waste. Renew. Energ. $31,2385-2392$. 
Moorhead, K.K., Nordstedt, R.A., 1993. Batch anaerobic digestion of water hyacinth effects of particle size, plant nitrogen content, and inoculum volume. Bioresour. Technol. 44, 71-76.

Müller, W., Wallmann, R., Fricke, K., 2001. Anaerobic digestion as an integrated part of a bio-mechanical waste treatment process. Proceedings of 8 th International Waste Management and Landfill Symposium, Cagliari, Italy, 1-5 October 2001. Vol 1, pp. 415-424.

Nopharatana, A., Pullammanappalli, P.C., Clarke, W.P., 2007. Kinetics and dynamic modelling of batch anaerobic digestion of municipal solid waste in a stirred reactor. Waste Manage. 27, 595-603.

Palmowski, L.M., Müller, J.A., 2003. Anaerobic degradation of organic materials significance of the substrate surface area. Water Sci. Technol. 47, 231-238.

Perez Lopez, C., Kirchmayr, R., Neureiter, M., Braun, R., 2005. Effect of physical and chemical pre-treatments on methane yield from maize silage and grains. Proceedings of 4th International Symposium on Anaerobic Digestion of Solid Waste, Copenhagen, Denmark, 31 August - 2 September 2005. Vol 2, pp. 204-208. Ripley, L.E., Boyle, W.C., Converse, J.C., 1986. Improved alkalimetric monitoring for anaerobic digestion of high-strength wastes. J. Water Pollut. Control. Fed. 58, 406411.

Sanders, W.T.M., Geerink, M., Zeeman, G., Lettinga, G., 2000. Anaerobic hydrolysis kinetics of particulate substrates. Water Sci. Technol. 41, 17-24.

Sharma, S.K., Mishra, I.M., Sharma, M.P., Saini, J.S., 1988. Effect of particle size on biogas generation from biomass residues. Biomass 17, 251-263. 
Ten Brummeler, E., 1999. Full scale experience with the Biocel-process, in: MataAlvarez, J., Tilche, A., Cecchi, F. (Eds.), Proceedings of the 2nd International Symposium on anaerobic digestion of solid waste, Barcelona, Spain, 15-17 June 1999. Vol 1, pp. 308-314.

Vandevivere, P., De Baere, L., Verstrate, W., 2003. Types of anaerobic digester for solid wastes, in: Mata-Alvarez, J. (Eds.), Biomethanisation of the organic fraction of municipal solid wastes. IWA Publishing, London, pp. 111-140.

von Blottnitz, H., Pehlken, A., Pretz, T., 2002. The description of solid wastes by particle mass instead of particle size distributions. Resour. Conserv. Recy. 34, 193 207.

Walker, M., Zhang, Y., Heaven, S., Banks, C.J., 2009. Potential errors in the quantitative evaluation of biogas production in anaerobic digestion processes. Bioresour. Technol. 100, 6339-6346.

Yadvika, Santosh, Sreekrishnan, T.R., Kohli, S., Rana, V., 2004. Enhancement of biogas production from solid substrates using different techniques - a review. Bioresour. Technol. 95, 1-10. 


\section{Table 1}

Characteristics of the different batches of feedstock.

\begin{tabular}{llll}
\hline Parameter & Mean value \pm Standard & Minimum value & Maximum value \\
& deviation & & \\
\hline $\mathrm{pH}$ & $4.9 \pm 0.7$ & 4.2 & 5.9 \\
$\mathrm{TS}(\%$ of fresh matter) & $48.2 \pm 4.1$ & 44.0 & 54.3 \\
VS (\% of fresh matter) & $39.2 \pm 0.2$ & 36.5 & 42.4 \\
TAN (mg N kg ${ }^{-1}$ fresh matter) & $1300 \pm 600$ & 900 & 2000 \\
VFA (mg kg & & \\
& $3700 \pm 1900$ & 2200 & 6400
\end{tabular}

${ }^{1}$ VFA equals the sum of the concentration of acetic, propionic, n-butyric, iso-butyric, n-valeric, isovaleric, hexanoic and heptanoic acids as measured by gas chromatograph. 


\section{Table 2}

Summary of experimental results for wet digesters fed with waste of different particle size distribution at different OLR (Coarse waste was dry processed by shear shredder, and fine size waste was shredded then wet processed using a macerating grinder).

\begin{tabular}{|c|c|c|c|c|c|c|c|c|}
\hline & $\mathbf{P S}^{1}$ & Organic lo & ding rate ( & $\mathrm{VS} \mathrm{m^{-3 }} \mathrm{da}$ & & & & \\
\hline & & 2 & 3 & 4 & 4.5 & 5 & 5.5 & 6 \\
\hline $\mathrm{SBP}^{1}$ & Coarse & $0.46 \pm 0.02$ & $0.56 \pm 0.06$ & $0.54 \pm 0.04$ & $0.55 \pm 0.03$ & $0.53 \pm 0.02$ & $0.52 \pm 0.02$ & $0.54 \pm 0.03$ \\
\hline & Fine & $0.43 \pm 0.03$ & $0.54 \pm 0.03$ & $0.54 \pm 0.03$ & $0.57 \pm 0.02$ & $0.56 \pm 0.02$ & $0.52 \pm 0.01$ & -- \\
\hline $\mathrm{SMP}^{1}$ & Coarse & $0.25 \pm 0.01$ & $0.33 \pm 0.01$ & $0.31 \pm 0.02$ & $0.30 \pm 0.02$ & $0.30 \pm 0.01$ & $0.29 \pm 0.02$ & $0.32 \pm 0.02$ \\
\hline & Fine & $0.24 \pm 0.02$ & $0.32 \pm 0.02$ & $0.32 \pm 0.02$ & $0.32 \pm 0.01$ & $0.32 \pm 0.01$ & $0.30 \pm 0.02$ & -- \\
\hline $\mathrm{VBP}^{1}$ & Coarse & $0.93 \pm 0.05$ & $1.7 \pm 0.1$ & $2.1 \pm 0.2$ & $2.4 \pm 0.2$ & $2.7 \pm 0.1$ & $2.9 \pm 0.1$ & $3.3 \pm 0.2$ \\
\hline & Fine & $0.87 \pm 0.05$ & $1.7 \pm 0.1$ & $2.2 \pm 0.1$ & $2.5 \pm 0.1$ & $2.8 \pm 0.1$ & $2.9 \pm 0.1$ & -- \\
\hline $\mathrm{CH}_{4}{ }^{1}$ & Coarse & $55.2 \pm 0.6$ & $56.9 \pm 0.5$ & $58.4 \pm 1.4$ & $57.0 \pm 1.0$ & $56.4 \pm 1.0$ & $56.5 \pm 1.7$ & $58.7 \pm 1.1$ \\
\hline & Fine & $55.3 \pm 1.0$ & $59.0 \pm 1.2$ & $59.3 \pm 0.7$ & $57.8 \pm 1.0$ & $58.1 \pm 0.8$ & $56.2 \pm 1.3$ & -- \\
\hline $\mathrm{VSR}^{1}$ & Coarse & $66 \pm 1$ & $71 \pm 0$ & $63 \pm 2$ & $66 \pm 1$ & $67 \pm 1$ & $63 \pm 2$ & $64 \pm 1$ \\
\hline & Fine & $61 \pm 1$ & $69 \pm 1$ & $62 \pm 1$ & $64 \pm 1$ & $64 \pm 1$ & $63 \pm 0$ & -- \\
\hline $\mathrm{pH}$ & Coarse & $7.3 \pm 0.0$ & $7.2 \pm 0.1$ & $7.1 \pm 0.1$ & $7.2 \pm 0.1$ & $7.3 \pm 0.0$ & $7.3 \pm 0.1$ & $7.3 \pm 0.1$ \\
\hline & Fine & $7.3 \pm 0.1$ & $7.3 \pm 0.0$ & $7.1 \pm 0.1$ & $7.1 \pm 0.1$ & $7.3 \pm 0.0$ & $7.3 \pm 0.1$ & -- \\
\hline VFA $^{1}$ & Coarse & $<10$ & $20 \pm 10$ & $50 \pm 10$ & $40 \pm 10$ & $60 \pm 10$ & $40 \pm 10$ & $80 \pm 20$ \\
\hline & Fine & $<10$ & $20 \pm 10$ & $50 \pm 20$ & $30 \pm 10$ & $50 \pm 10$ & $30 \pm 0$ & -- \\
\hline $\mathrm{IA} / \mathrm{PA}^{1}$ & Coarse & $0.27 \pm 0.02$ & $0.28 \pm 0.03$ & $0.46 \pm 0.03$ & $0.34 \pm 0.04$ & $0.32 \pm 0.02$ & $0.30 \pm 0.04$ & $0.27 \pm 0.07$ \\
\hline & Fine & $0.28 \pm 0.02$ & $0.30 \pm 0.02$ & $0.49 \pm 0.04$ & $0.39 \pm 0.03$ & $0.31 \pm 0.04$ & $0.35 \pm 0.03$ & -- \\
\hline
\end{tabular}

\footnotetext{
${ }^{1}$ PS: particle size range of the associated mechanical size reduction pre-treatment to the digester feedstock;

SBP: specific biogas production, $\mathrm{m}^{3} \mathrm{~kg}^{-1} \mathrm{VS}$ added; SMP: specific methane production, $\mathrm{m}^{3} \mathrm{CH}_{4} \mathrm{~kg}^{-1} \mathrm{VS}$ added;

VBP: volumetric biogas production, $\mathrm{m}^{3} \mathrm{~m}^{-3}$ day ${ }^{-1} \mathrm{CH}_{4}$ : methane content, \%; VSR: volatile solids removal, \%;

VFA: volatile fatty acids, $\mathrm{mg}^{-1}$; IA/PA: Ripley ratio of intermediate to partial alkalinity.
} 


\section{Table 3}

Performance of wet and dry digestion at OLR $6 \mathrm{~kg} \mathrm{VS} \mathrm{m}^{-3}$ day $^{-1}$, when fed on the double-shredded and single-shredded materials, respectively.

\begin{tabular}{lll}
\hline Parameter & Dry & Wet \\
\hline Specific biogas production $\left(\mathrm{STP} \mathrm{m}^{3} \mathrm{~kg}^{-1} \mathrm{VS}_{\text {added }}\right)$ & $0.48 \pm 0.05$ & $0.54 \pm 0.03$ \\
Specific methane production $\left(\mathrm{STP} \mathrm{m}^{3} \mathrm{CH}_{4} \mathrm{~kg}^{-1} \mathrm{VS}_{\text {added }}\right)$ & $0.29 \pm 0.03$ & $0.32 \pm 0.02$ \\
Volumetric biogas production $\left(\mathrm{STP} \mathrm{m}^{3} \mathrm{~m}^{-3} \mathrm{~d}^{-1}\right)$ & $2.9 \pm 0.3$ & $3.3 \pm 0.2$ \\
Volatile solids removal (\%) & $57 \pm 4$ & $64 \pm 1$ \\
Biogas methane content (\%) & $59 \pm 1$ & $59 \pm 1$ \\
$\mathrm{pH}$ & $8.4 \pm 0.1$ & $7.3 \pm 0.1$ \\
VFA (mg kg & \\
TAN (mg NH & & $80 \pm 20$ \\
\end{tabular}




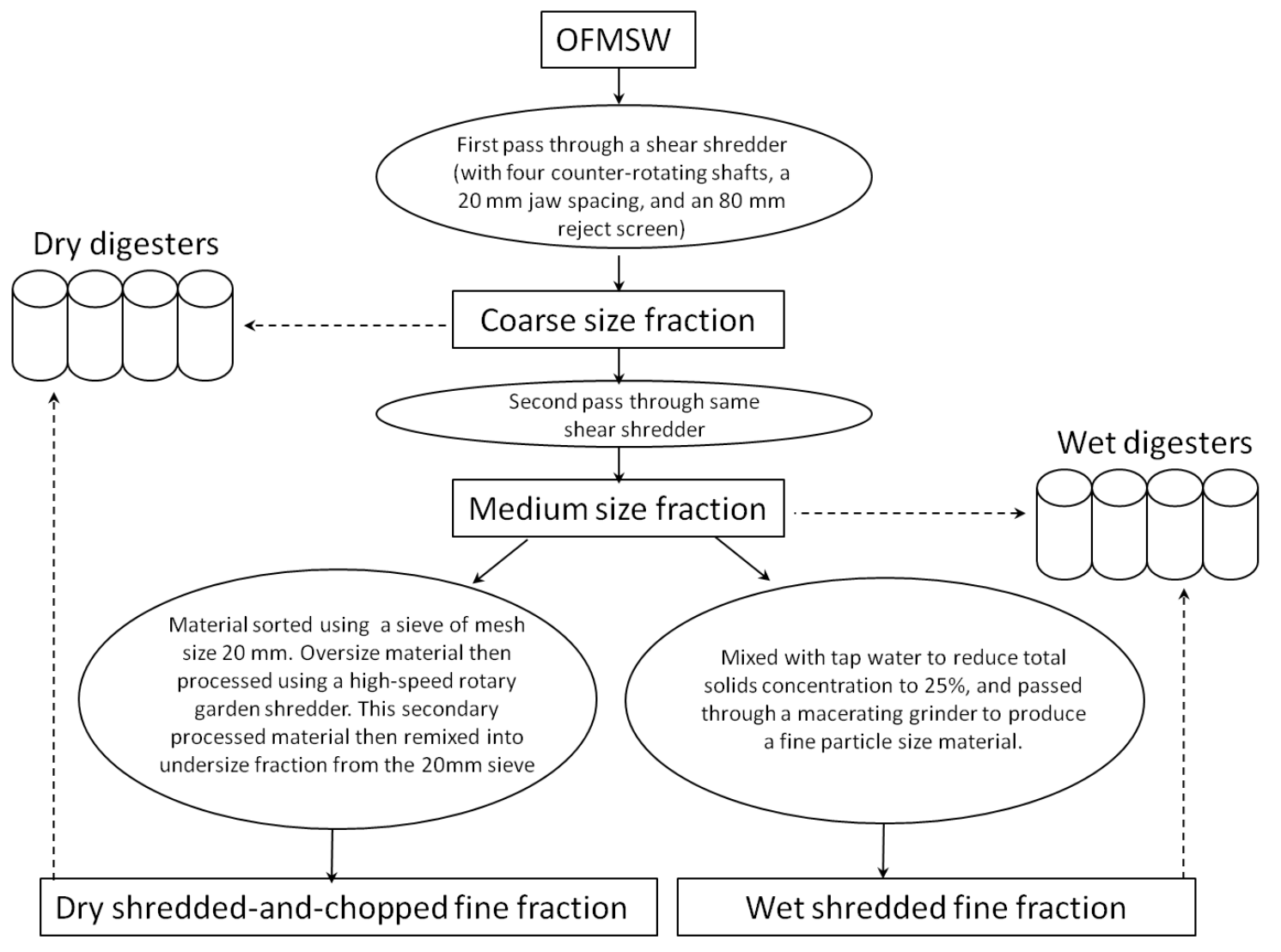

Fig. 1. Scheme of mechanical particle size reduction pre-treatment processes. 


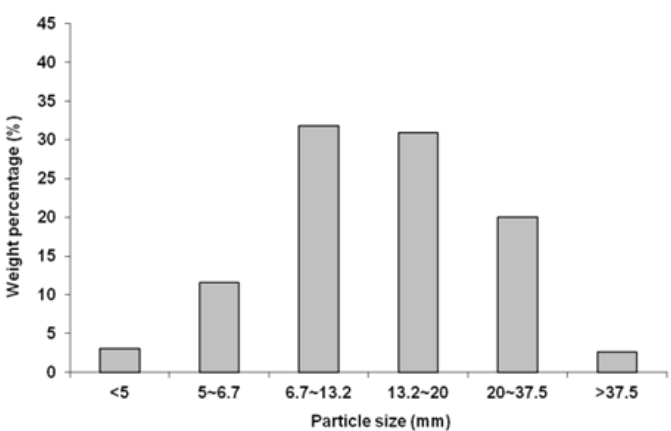

a. Single pass through shear shredder

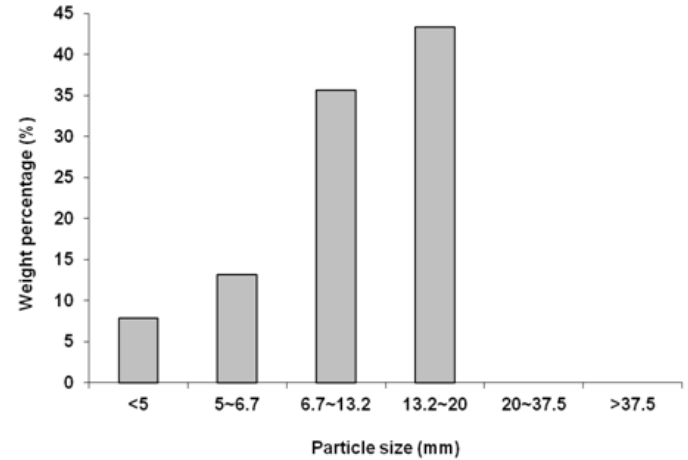

c. Doublepass through shear shredder and reduction of material larger than $20 \mathrm{~mm}$ with rotary cutter

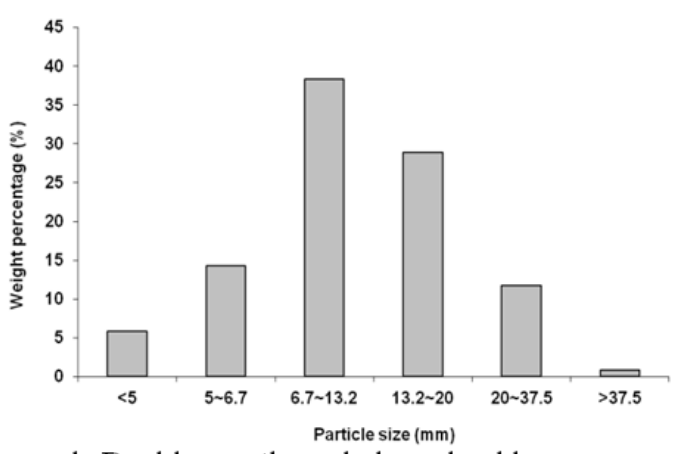

b. Doublepass through shear shredder

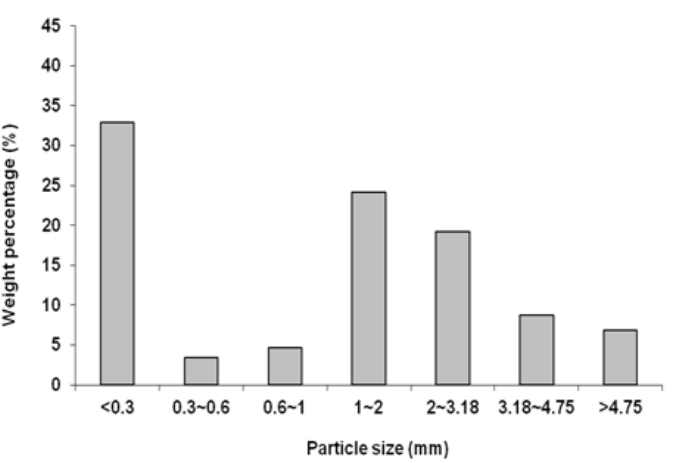

d. Doublepass through shear shredder and further reduction of size using wet macerating grinder

Fig. 2. Particle size analysis on size-reduced OFMSW used in this anaerobic digestion study. 


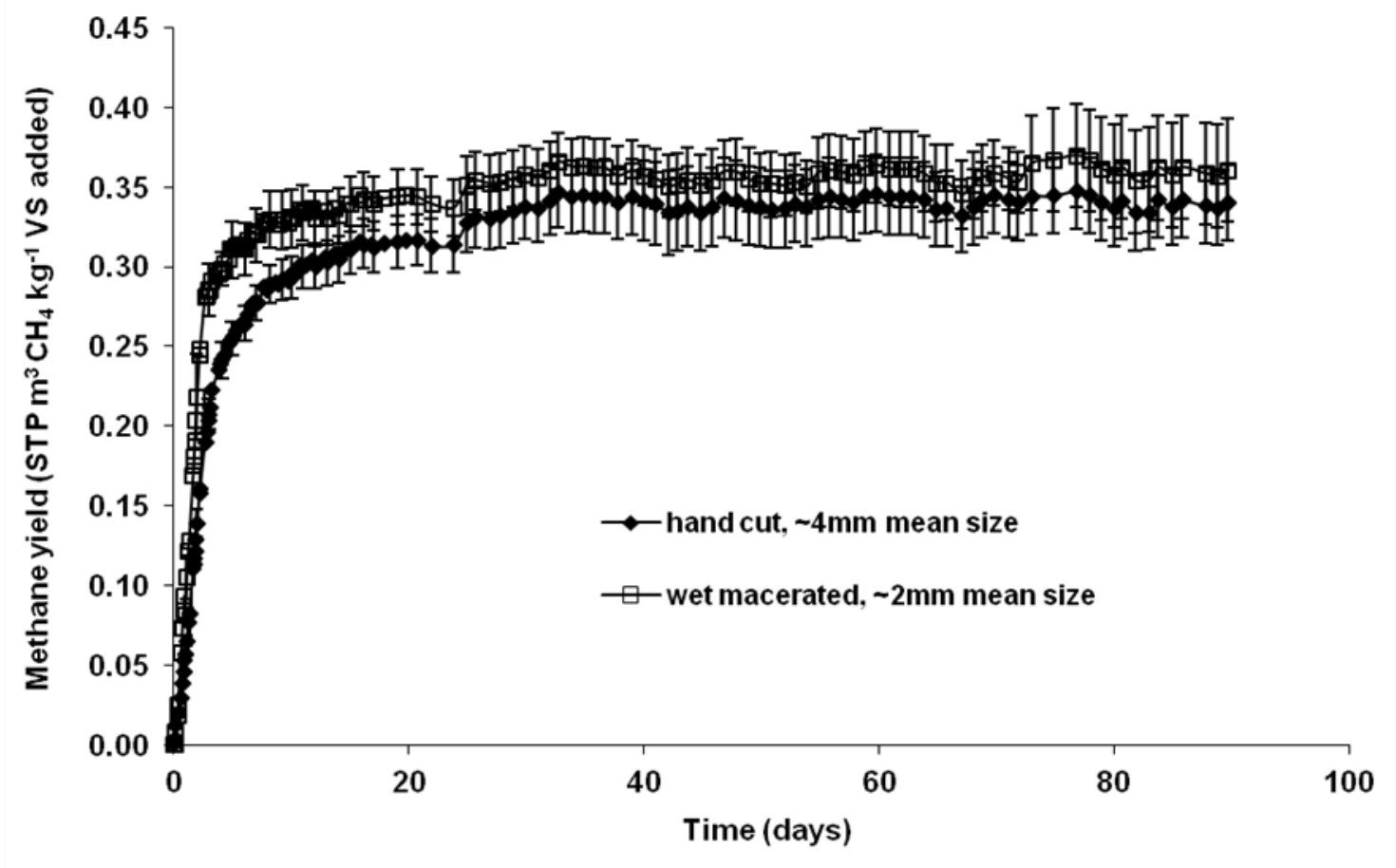

Fig. 3. BMP assay of OFMSW with particle size reduction by different methods. 


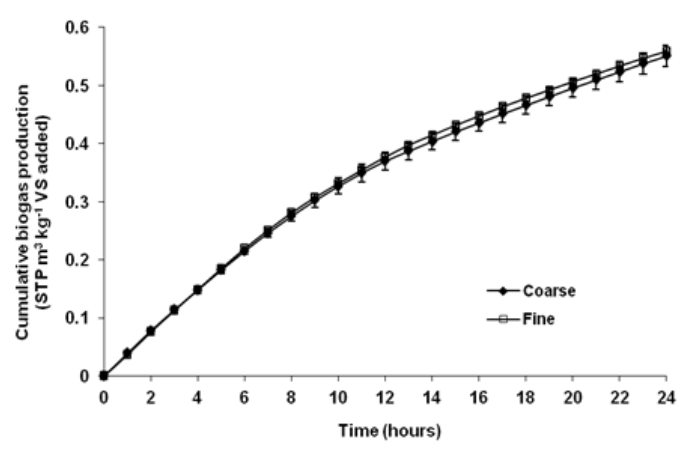

a. OLR $3.0 \mathrm{~kg} \mathrm{VS} \mathrm{m}^{-3} \mathrm{~d}^{-1}$

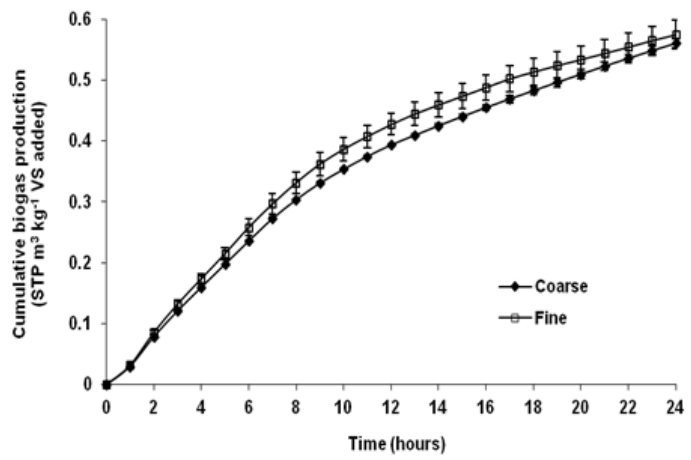

c. OLR $4.5 \mathrm{~kg} \mathrm{VS} \mathrm{m}^{-3} \mathrm{~d}^{-1}$

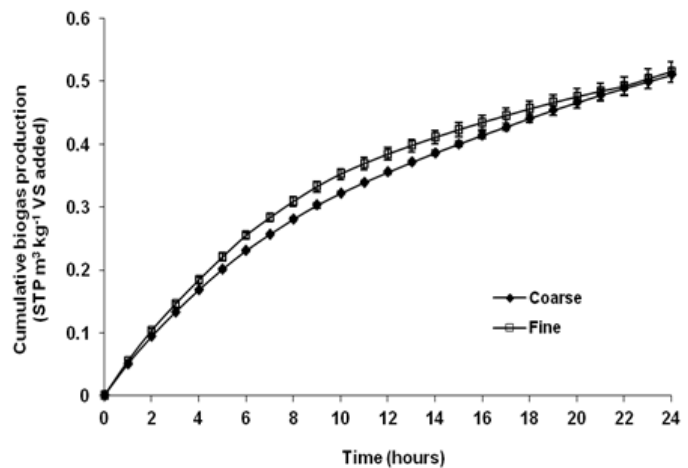

e. OLR $5.5 \mathrm{~kg} \mathrm{VS} \mathrm{m}^{-3} \mathrm{~d}^{-1}$

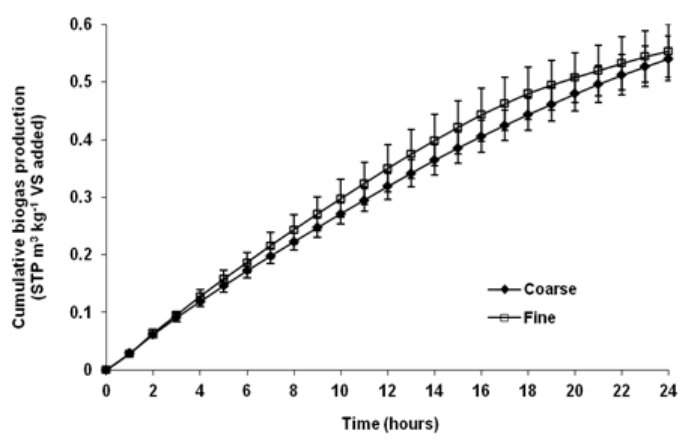

b. OLR $4.0 \mathrm{~kg} \mathrm{VS} \mathrm{m} \mathrm{m}^{-3} \mathrm{~d}^{-1}$

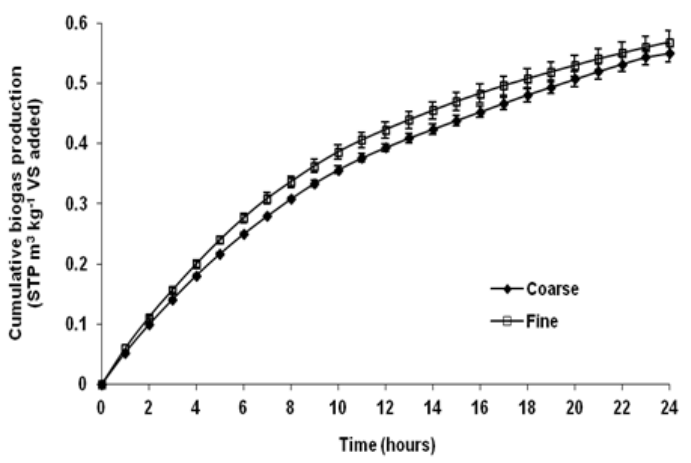

d. OLR $5.0 \mathrm{~kg} \mathrm{VS} \mathrm{m} \mathrm{m}^{-3} \mathrm{~d}^{-1}$

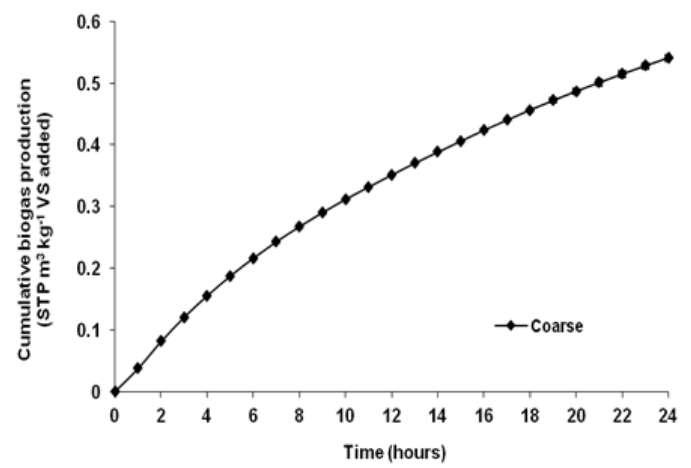

f. OLR $6.0 \mathrm{~kg} \mathrm{VS} \mathrm{m}^{-3} \mathrm{~d}^{-1}$

Fig. 4. Typical daily cumulative biogas production at different loading rates (Coarse waste was dry processed by shear shredder, and fine size waste was shredded then wet processed using a macerating grinder). 


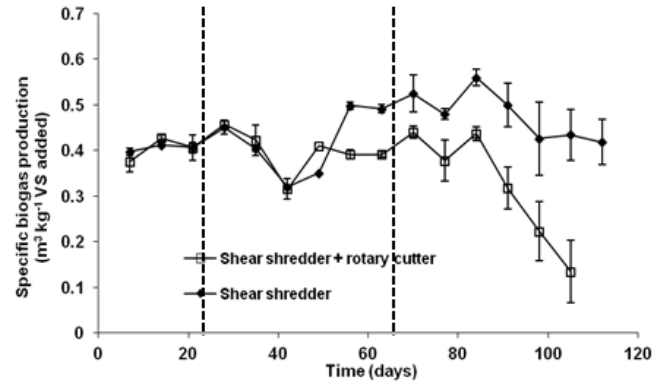

a. Specific biogas production

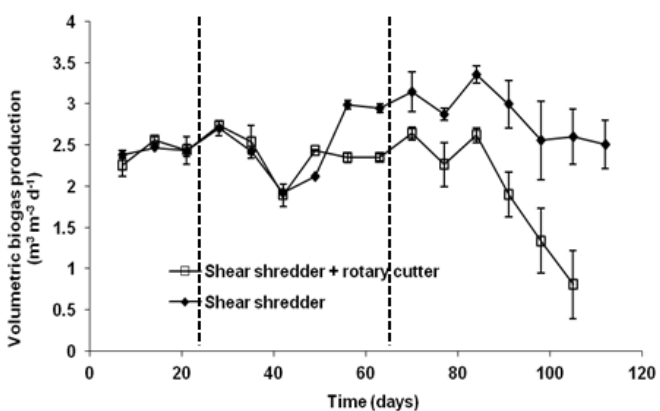

c. Volumetric biogas production

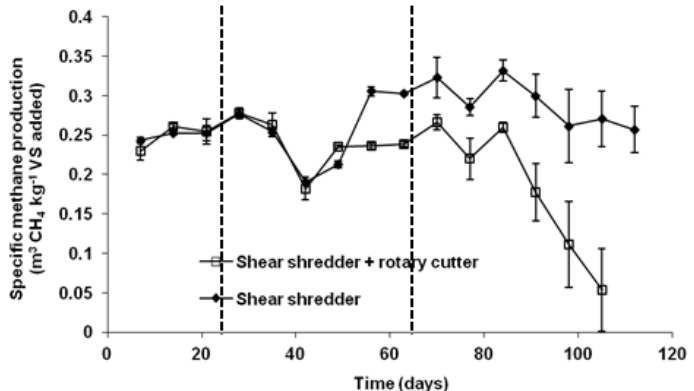

b. Specific methane production

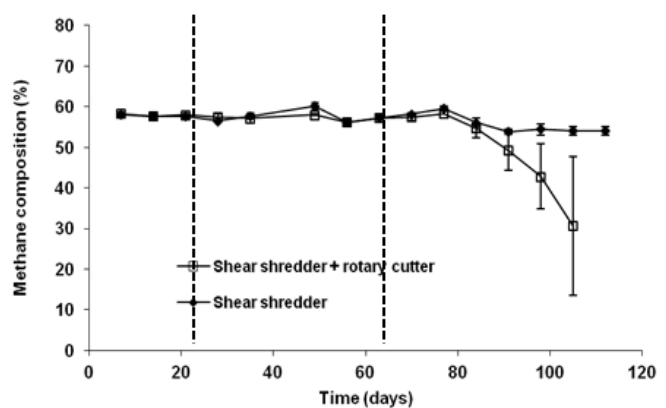

d. Biogas methane content

Fig. 5. Biogas production profiles in dry digesters (Vertical dashed lines indicate when a change in input material took place as a result of a fresh batch of feedstock). 


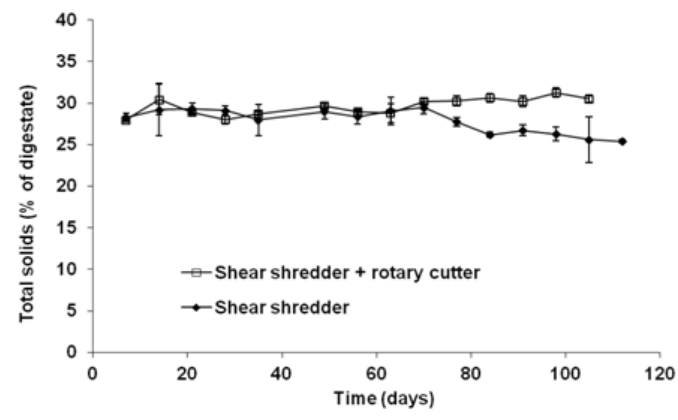

a. Total solids (TS)

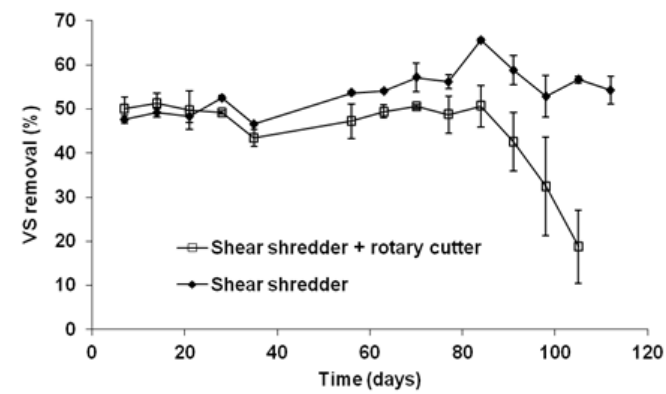

c. Volatile solids removal

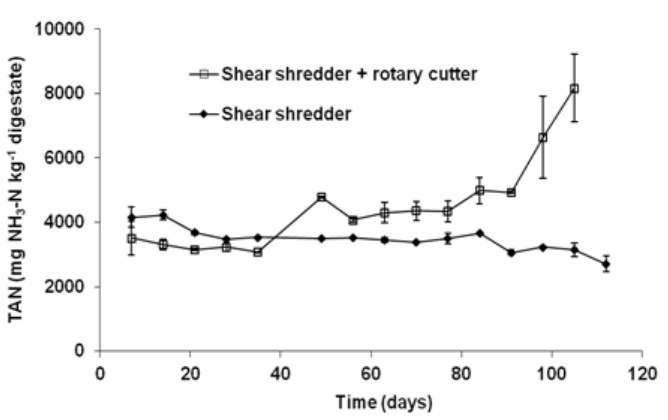

e. Total ammoniacal nitrogen (TAN)

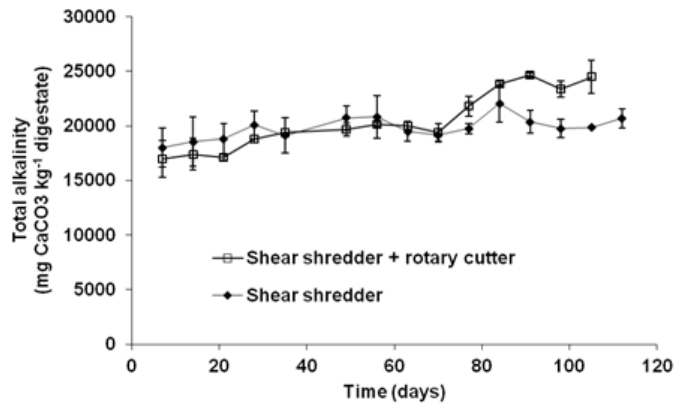

g. Total alkalinity

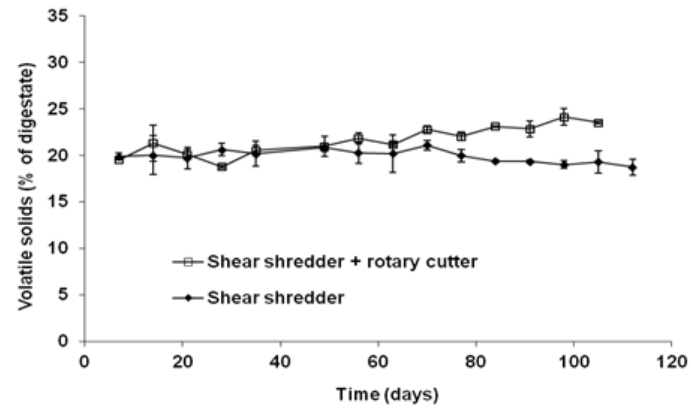

b. Volatile solids (VS)

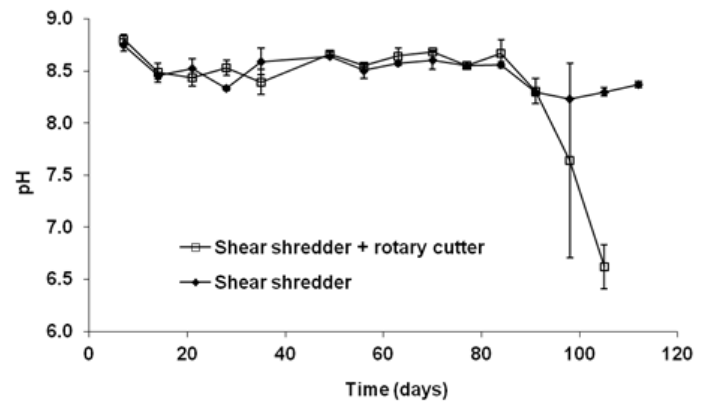

d. $\mathrm{pH}$

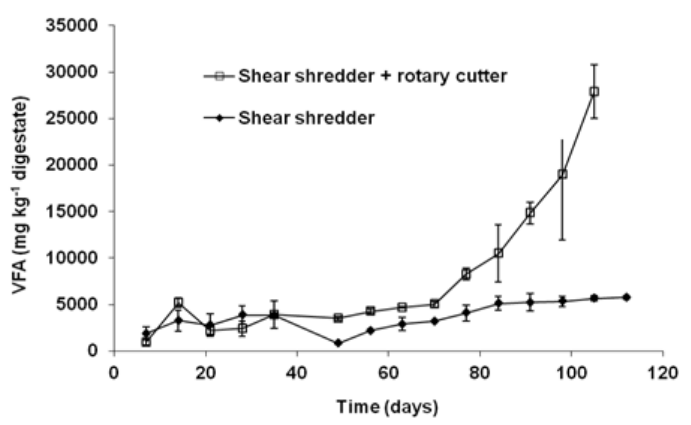

f. Total volatile fatty acids (VFA)

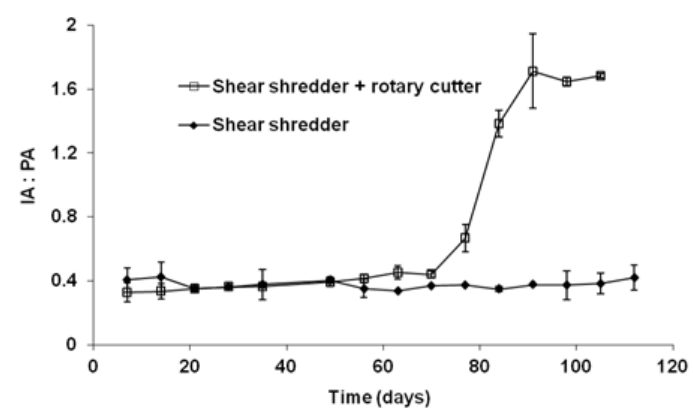

h. Ratio of immediate to partial alkalinity (IA:PA)

Fig. 6. Digestate TS, VS, pH, TAN, VFA, and alkalinity profiles in dry digesters. 


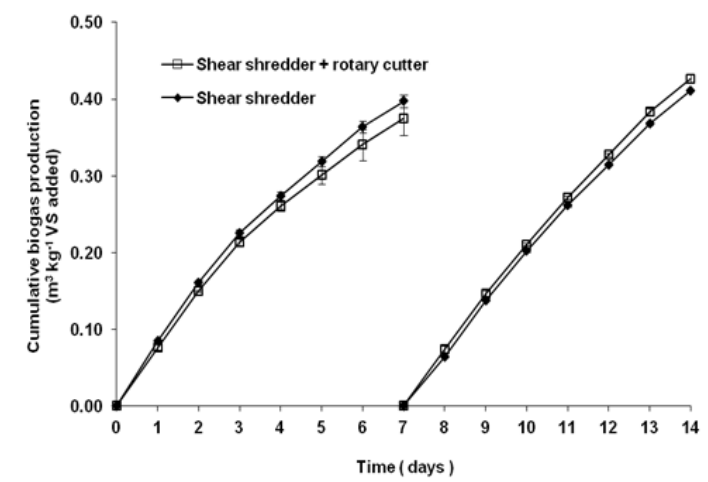

a. Cumulativebiogas production

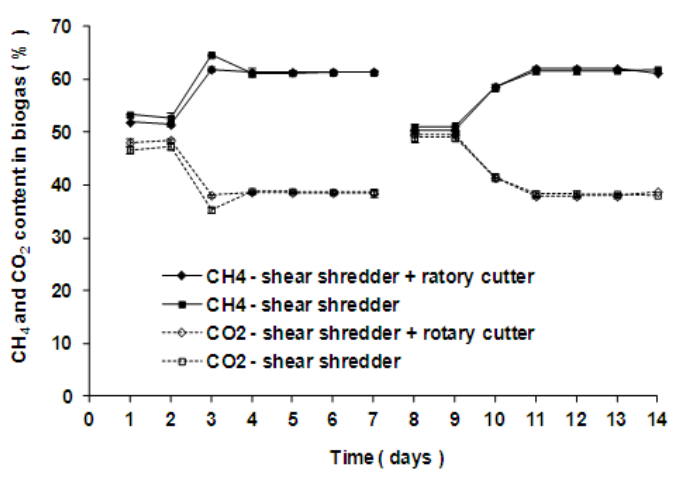

b. Biogas composition

Fig. 7. Cumulative biogas production and composition profiles in typical two consecutive feeding cycles in dry digesters. 


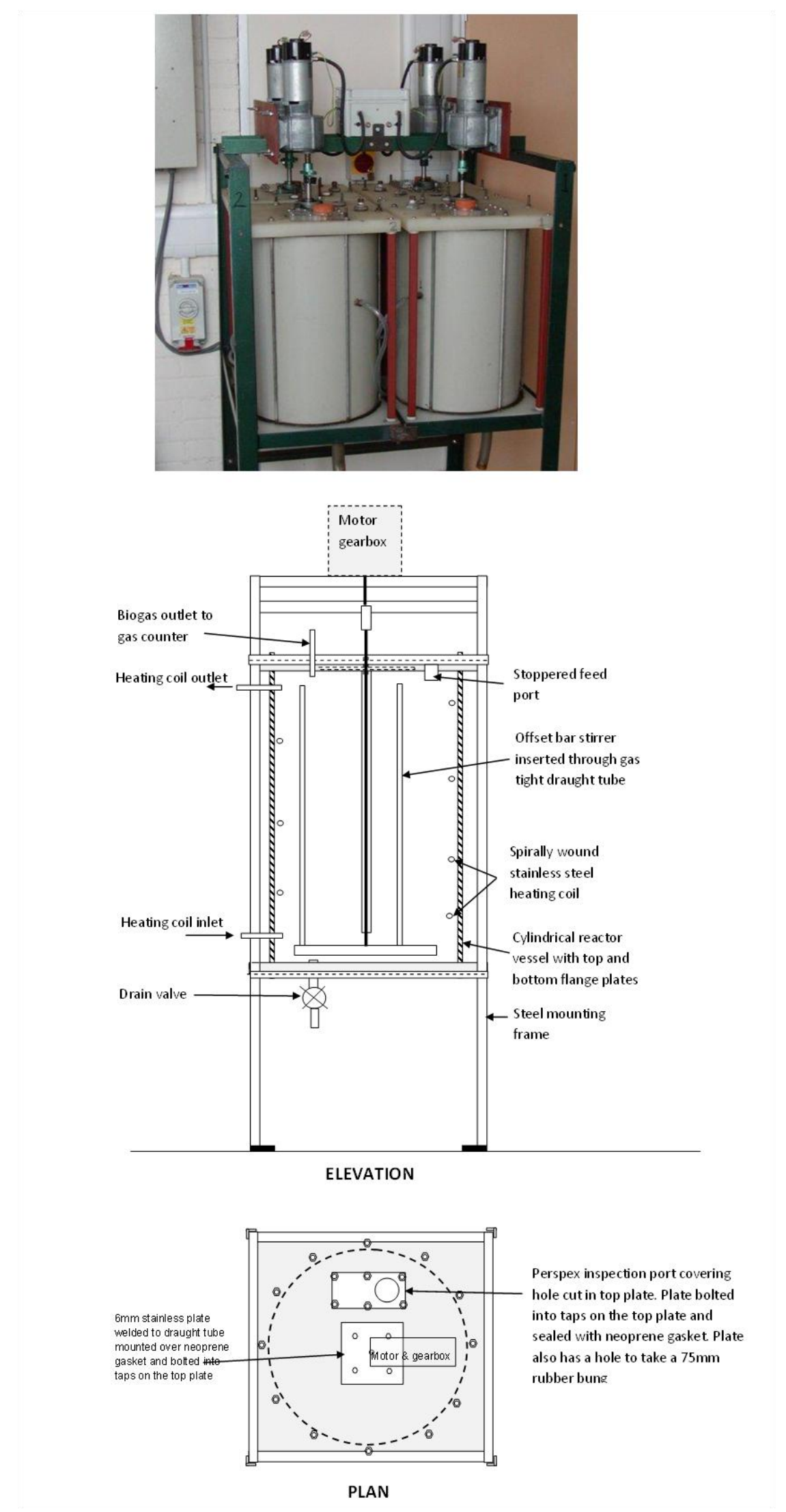

Supplementary Figure 1. Image and Diagram of wet digesters 


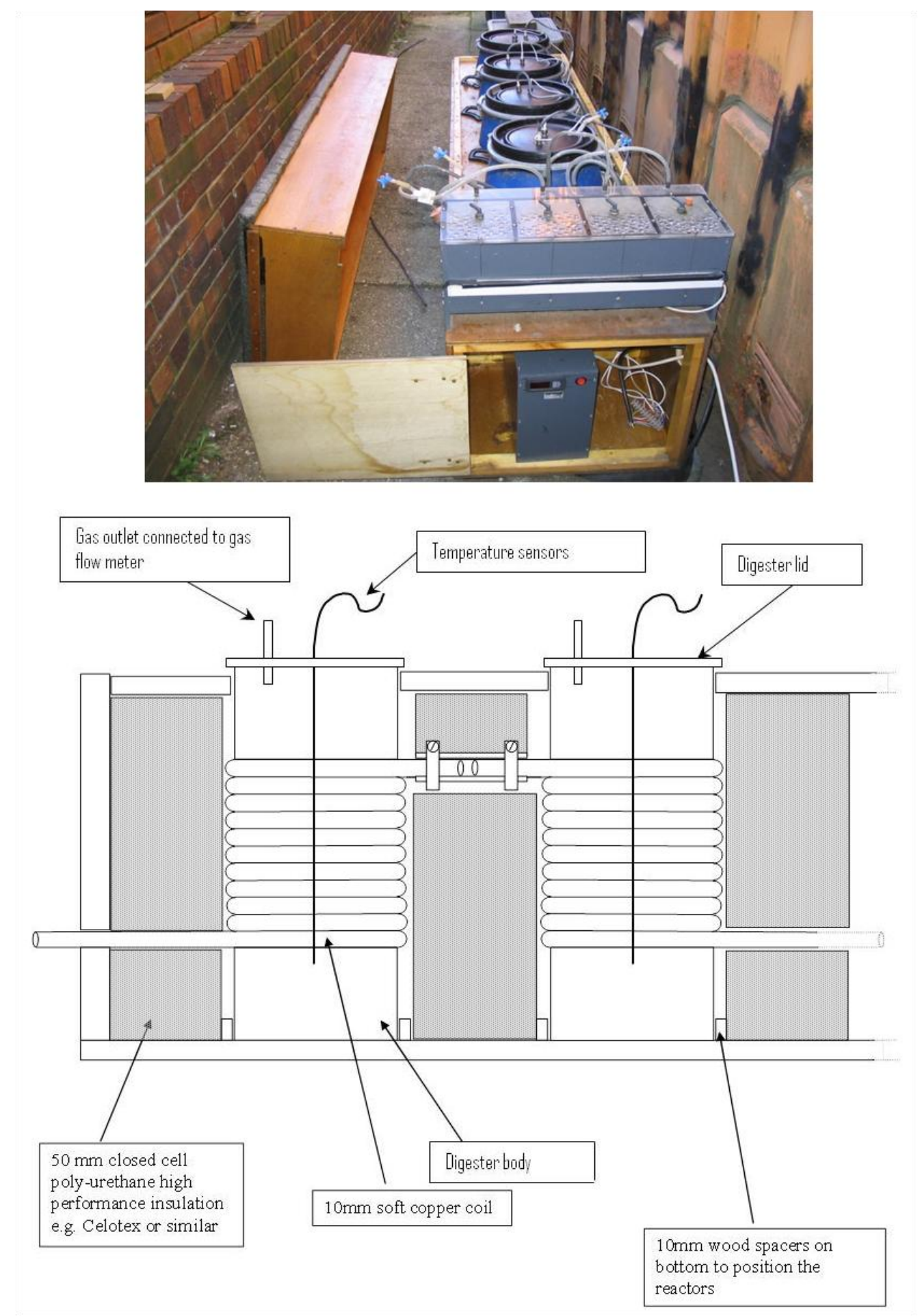

Supplementary Figure 2. Image and Diagram of dry digesters 